\title{
A LITERATURA INFANTIL E JUVENIL CONTEMPORÂNEA E O PODER DAS MÍDIAS SOCIAIS
}

Rosa Maria Cuba Riche (CAp-UERJ)

\begin{abstract}
"Os valores que a sociedade preconiza, ou os que considera prejudiciais, estão presentes nas diversas manifestações da ficção, da poesia e da ação dramática. A literatura confirma e nega, propõe e denuncia, apoia e combate, fornecendo a possibilidade de vivermos dialeticamente os problemas".
\end{abstract}

Antonio Candido

Resumo: A história da sociedade é marcada por momentos de transformações intensas. Assim a "primeira modernidade" está associada à Revolução Industrial, a "segunda modernidade", à era da cultura eletrônica e agora vive-se uma "terceira modernidade", com a disseminação das Tecnologias da Informação. O debate em pauta gira em torno da "sociedade em rede", da "era da informação" ou da "sociedade do conhecimento", tomada pelas redes de comunicação também chamada de "cibersociedade". Seus atores vivenciam mudanças profundas de comportamento, a partir do uso de equipamentos de informática associados à telecomunicação. Essa "terceira modernidade", própria de uma Terceira Revolução Industrial, é parte constitutiva de outro fenômeno, a globalização. A Internet é a grande responsável pela implementação dessa nova cultura e possibilitou a criação de meios massivos de comunicação, vistos por uns como maléficos, capazes de homogeneizar gostos, potencializar discussões, manipular opiniões e, por outros, como forma de manifestação do receptor, de construção e difusão de culturas. Este trabalho pretende discutir como a literatura voltada para crianças e jovens reflete esteticamente as transformações sociais e como as manifestações circunscritas à esfera individual ganham uma repercussão impensável, através do uso das mídias sociais, a partir da análise de três obras. São elas: Meninos sem pátria de Luiz Puntel (1988); O menino que espiava pra dentro de Ana Maria Machado (2008); Peppa de Silvana Rando (2009). O repertório teórico apoia-se principalmente nos estudos de Fuser (2005), Bolaño (1999), Candido (1968), Iser (1979), Casarin (2018), Molica (2018) entre outros.

Palavras-chave: Literatura Infantil/Juvenil; Mídias Sociais. 
Abstract: The history of society is marked by moments of intense transformation. Thus, the "first modernity" is associated with the Industrial Revolution, the "second modernity", with the era of electronic culture. Now we are experiencing a "third modernity" with the dissemination of Information Technologies. The debate on the agenda revolves around the "network society", the "information age" or the "knowledge society", also known as within communication networks also as "cybersociety". Its actors experience profound changes in behavior, from the use of computer equipment, associated with telecommunication. This "third modernity", characteristic of a Third Industrial Revolution, is part of another phenomenon, globalization. The Internet is largely responsible for the implementation of this new culture and has enabled the creation of massive means of communication, seen by some as evil, capable of homogenizing tastes, enhancing discussions, manipulating opinions and, on the other hand, as a way of informing the receiver as to construction and diffusion of cultures. This work intends to discuss how the literature aimed at children and young people aesthetically reflects social transformations and how the manifestations circumscribed to the individual sphere cause an unthinkable repercussion through the use of social media, from the analysis of three works. They are: Meninos sem pátria by Luiz Puntel (1988), O menino que espiava pra dentro by Ana Maria Machado (2008). Peppa by Silvana Rando (2009). The theoretical repertoire is based mainly on the studies of Fuser (2005), Bolaño (1999), Candido (1968), Iser (1979), Casarin (2018), Molica (2018) among others.

Keywords: Youth Literature; Social Media.

De acordo com os estudiosos, a história da sociedade é marcada periodicamente por momentos em que as transformações são mais intensas. Assim a "primeira modernidade" está associada à Revolução Industrial, com as estradas de ferro, a iluminação a gás, o telégrafo, a telefonia, conformando uma cultura tipográfica (diacrônica e linear), fundamentada na escrita (ORTIZ, 1991 Apud 
FUSER, 2005, p.39). Uma "segunda modernidade", a da era da cultura eletrônica, sincrônica e com múltiplas perspectivas é baseada num sistema técnico (automóvel, avião, eletricidade, telecomunicações). Vive-se agora uma "terceira modernidade", com a disseminação das Tecnologias da Informação e Comunicação, as chamadas TICs. O debate em pauta gira em torno da "sociedade em rede", da "era da informação" ou da "sociedade do conhecimento", tomada pelas redes de comunicação, garantidas pelo processo de informatização da sociedade, presente "em todas as esferas, desde o plano da política e do poder, até o das relações humanas mais sensíveis, como a afetividade" (FUSER, 2005, p.39). Os atores dessa sociedade vivenciam mudanças profundas de comportamento, a partir do uso de equipamentos de informática, associados à telecomunicação, elevados a um alto grau de sofisticação e em perspectiva de convergência tecnológica que, segundo esse estudioso, "apontaria para uma cibersociedade" (FUSER, 2005, p.39).

A intensificação do uso dessas tecnologias implica, portanto, em uma mudança ampla e variada no cotidiano das pessoas que pode ser notada de múltiplas formas, tornando-se quase impossível prescindir delas no mundo do trabalho, do lazer, da comunicação e do consumo. Essa 
"terceira modernidade", própria de uma Terceira Revolução Industrial - que tem como uma de suas características o "peso crescente do complexo eletrônico", como apontou Coutinho Apud Bolaño (1999, p.73) - é parte constitutiva de outro fenômeno, a globalização. Segundo Bolaño, a globalização: "não é outra coisa senão o auge da internacionalização do capital monopolista, a indústria cultural é o ponto de partida para a constituição de uma cultura capitalista mundial que se expande (Apud FUSER, 2005, p.40).

Sem dúvida, a Internet é a grande responsável pela implementação dessa nova cultura. Originalmente criada em 1969, com o objetivo de garantir a comunicação militar e científica nos Estados Unidos, em caso de guerra nuclear, ganhou outros usos e hoje é responsável por facilitar a comunicação entre as pessoas, com o correio eletrônico, favorecer o comércio nas vendas em rede (e-comerce), a educação a distância, as consultas variadas, o intercâmbio de conhecimentos nas pesquisas nas mais diversas áreas. Ela é a base da sociedade em rede e possibilitou a criação de meios massivos de comunicação, vistos por uns como maléficos, capazes de homogeneizar gostos, potencializar discussões, manipular opiniões e, por outros, como forma de manifestação do receptor de construção e difusão de culturas. 
A literatura voltada para crianças e jovens, assim como outras formas de manifestações artísticas, reflete esteticamente as transformações sofridas pela sociedade em que está inserida. Assim temas e problemas vigentes ganham as páginas das obras destinadas preferencialmente a esse público. Em uma "sociedade em rede" e em plena "era da informação" como preconizam os estudiosos, as manifestações circunscritas à esfera individual até então ganham uma repercussão impensável através do uso das mídias sociais.

Nesse sentido, uma leitura de uma obra passa a representar a leitura, ganha simpatizantes que com seus likes e comentários vão disseminando um ponto de vista, muitas vezes apressado sobre a obra. A literatura infantil e juvenil tem sofrido na pele o poder dessas mídias que acabam por condenar à "fogueira" obras que em muito podem contribuir para a formação de um sujeito leitor mais crítico. A lista dessas obras "condenadas" cresce a cada dia e não poupa nem os autores já devidamente consagrados pela crítica, considerados clássicos e importantes para a formação do repertório cultural do leitor em formação. Obras de autores como Machado de Assis e Monteiro Lobato, para citar apenas dois dos mais representativos da nossa literatura, são 
revisitadas sem a devida contextualização da época em que foram escritas, analisadas de forma aligeirada e superficial.

Mais recentemente, o escritor Luiz Puntel também se viu envolvido em uma polêmica quando seu livro Meninos sem pátria, escrito em 1981, teve a adoção suspensa por uma das instituições de ensino mais tradicionais do Rio de Janeiro por conta da reação dos pais de alunos que consideraram a história uma apologia ao comunismo e, portanto, nociva aos alunos do 6ㅇ ano do ensino fundamental. Certamente o autor não imaginava que, 37 anos depois de sua publicação, a obra seria suspensa em uma escola e retirada da lista de leitura dos estudantes.

O livro, publicado pela editora Ática e já em sua 23ạ edição é um dos títulos mais vendidos da clássica Coleção Vaga-Lume, que contribuiu para a formação de leitores nas décadas de 80 e 90 . O autor publicou outros títulos que fazem parte dessa mesma coleção, dentre eles Açúcar Amargo e 0 grito do Hip Hop, indicado ao Prêmio Jabuti em 2005.

O enredo de Meninos sem pátria narra a história de uma família que se vê obrigada a deixar o Brasil após a redação do jornal em que o pai, que é jornalista, trabalhava, ser invadida. O narrador é um dos filhos do casal, com dez anos incompletos, que vivencia os temores e angústias diante da 
necessidade de a família partir para o exílio no Chile. Pela voz desse narrador mirim, o leitor acompanha a fuga precipitada do pai, a viagem de ônibus do restante da família até Campo Grande, o encontro com o pai na Bolívia, as agruras vividas para conseguir a documentação na comissão de Direitos Humanos para atravessar a fronteira do Brasil em direção ao Chile, momentos de tensão que geram desequilíbrio no enredo.

Uma segunda reviravolta ocorre com a queda do presidente Allende e a invasão da casa da família pelos carabineiros em busca do pai que se tornara "muito ativo dentro do processo político chileno" (PUNTEL, 1988, p.38). Nesse país, vivenciam o regime do ditador Augusto Pinochet e, por conta da perseguição aos contrários ao regime, são obrigados a se exilar na embaixada da França, a mais próxima da casa da família, até fugirem novamente, mas dessa vez para esse país. Veja-se o trecho:

Tempos difíceis aqueles: ainda estava bem claro em minha mente os tempos de Canaviápolis, nós jogando bola na rua, despreocupados. De repente começamos a nos despedaçar pela América do Sul, deixando um pouco no friorento Chile e, agora, íamos nos despedaçar pela Europa, em uma excursão forçada, tipo ida sem volta. (1988, p.47) 
Conforme o título sugere, a obra retrata a infância dos personagens longe de casa e termina com a volta da família ao Brasil, depois da anistia. Em razão de sua adoção em escolas, já tinham sido vendidos na ocasião dos protestos cerca de três milhões de exemplares de livros do autor.

Luiz Puntel, na época em que se instaurou a polêmica em torno do livro, em entrevista ao jornalista Fernando Molica da revista Veja disse:

Ter ficado surpreso com a medida, afirmou que nunca teve problema com a obra, lançada ainda durante o regime militar e adotada em diversas escolas há quase quarenta anos. Ele atribuiu a suspensão à radicalização política do país. O livro é inspirado no caso do jornalista José Maria Rabelo, que, perseguido pela ditadura, fugiu do país com a mulher e sete filhos. Na história, o personagem - que recebeu o nome de José Maria - tem dois filhos e se exilou no Chile e na França. (2018, s/p.)

Muitos editores, escritores e educadores se posicionaram contrários à ofensiva contra o livro. Basta fazer uma busca pelo nome do autor ou do título do livro na Internet para se ter noção da repercussão do fato e das centenas de declarações lamentando a postura tanto dos pais quanto da escola.

Em entrevista ao site Lunetas, o autor, compositor e ilustrador de livros infantis Ivan Zigg lamentou o silêncio 
da escola sobre a questão, pontuando a importância de as pessoas se organizarem enquanto sociedade civil para fazer valer os direitos da liberdade de expressão e pensamento crítico que a arte como linguagem pressupõe (LUNETAS, 2018, s/p.).

Ex-alunos e profissionais das áreas da educação e da literatura também se manifestaram no Facebook da escola com comentários contrários à situação e críticas à postura da instituição, alegando que a suspensão deveria ser encarada como censura. O site publicou à época:

A repercussão na página chegou inclusive aos próprios envolvidos diretamente na trama do livro, que foi inspirado em um uma história real, o exílio vivido pela família Rabelo. "Estou disposto a ir até a escola para conversar com os professores e explicar melhor a nossa história, e o que sofremos no exílio", comentou Ricardo Rabelo, ele próprio um dos personagens da obra de Luiz Puntel. (LUNETAS, 2018, s/p.)

Em setembro de 2018, mesmo ano em que o livro de Puntel foi "condenado", a autora Ana Maria Machado viveu situação parecida em relação ao livro $O$ menino que espiava pra dentro, acusado de fazer apologia ao suicídio. Publicado em 1983, ele também se tornou assunto central de uma série de postagens nas redes sociais (LUNETAS, 2018). 
O enredo tem como protagonista Lucas, um menino que é filho único e, como as crianças de sua idade, tem imaginação fértil, facilidade de sonhar outros mundos e se transportar para eles, através da imaginação. Seu interlocutor é o amigo imaginário Talento ou Tamanco ou Tatá. "Espiar para dentro" era o que mais gostava de fazer. Assim para passar mais tempo nesse mundo imaginário, bola um plano com o amigo. Para isso, recorre ao enredo dos contos maravilhosos da Bela Adormecida e do Príncipe Sapo em busca de uma fórmula para conseguir permanecer no mundo dos sonhos por mais tempo, tal como ocorreu com a Bela Adormecida.

A maçã foi o passaporte para o sono profundo. Assim, a cena do menino é narrada:

\begin{abstract}
Na hora de dormir, despediu-se de todos [...] e foi para a cama com a sua maçã. Deu uma mordida, engasgou com um pedaço, espiou para dentro - não tinha fim o seu espaço. Viu tantos lugares, nadou em tantos mares, voou pelos ares. Viu cavalos e castelos, viu bosques de caramelos, viu piratas e palhaços, viu vaqueiros e viu laços, viu automóveisleões, viu parques de diversões, viu carrossel de dragões. (MACHADO, 2008, p.25)
\end{abstract}

Vale ressaltar no trecho acima o ludismo da linguagem fruto da escolha vocabular, do jogo das repetições de palavras, das rimas que marcam a prosa da autora tão caros ao leitor com pouca experiência de leitura. 
A narrativa prossegue com o protagonista envolvido pela fantasia, vivenciando emoções quando a magia acontece, momento de maior intensidade dramática, e o menino mergulha no breu. Veja-se o trecho:

Não dava para espiar mais, para ver nada, nem na frente nem atrás. Só aquele breu profundo. Ele, de um lado.

Do outro, o mundo.

De repente, um beijo, um abraço, os olhos se abrindo, a luz brilhando no espaço.

Você é uma princesa?

A mãe riu:

- Ainda está dormindo, meu filho? Ande, acorde que está na hora de ir para a aula, chega de tanto sonhar. (2008, p.27-28)

Aos poucos o mundo real vai se descortinando aos olhos do menino. Veja-se o trecho: "E Lucas foi reconhecendo as paredes, os quadros, a cortina, os móveis de seu quarto. $E$ um resto de maçã caído do lado do travesseiro" (2008, p.28). Em seguida, a mãe anuncia um presente inesperado:

- Tem uma surpresa para você. Uma coisa que você vai adorar.

Não era uma coisa. Era um cachorro. Como ele tanto queria, há tanto tempo, desde antes do seu sono de séculos. (2008, p.28)

O cachorro é o seu novo amigo e companheiro nos momentos em que se isola para expiar para dentro. E, antes de sair para escola, quando a mãe pergunta como é que ele 
ia chamar, o menino responde: "Talento ou Tamanco. Mas pode chamar de Tatá" (MACHADO, 2008, p.30).

O enredo une as pontas da realidade e da fantasia, típicas de uma fase de vida em que elas se misturam sem cerimônia e se concretizam no amigo imaginário criado para fazer companhia nas brincadeiras desse período da infância e, no caso do personagem que é filho único, de alguma forma ocupar o lugar de um irmão.

A reação à obra, acusada de fazer apologia ao suicídio, ganhou espaço nas mídias sociais e pegou de surpresa a autora, que em 50 anos de carreira nunca tinha sofrido uma acusação desse tipo em relação aos seus livros. Em entrevista a Rodrigo Casarin, do blog Página Cinco, publicada em 7 de setembro de 2018, quando perguntada quais tipos de reflexões e discussões pensava em suscitar ou levantar com as crianças, esclarece:

Quando escrevo uma história, em grande parte o processo é inconsciente. Não fico procurando enviar mensagens. Mas é claro que cada história, simbolicamente, vai configurando uma rede de reflexões. Essa girava em torno de imaginação e realidade, e da solidão do filho único que quer um irmãozinho, cria um amigo imaginário, deseja cada vez mais viver num mundo de sonhos com esse personagem inventado, mas acaba ganhando dos pais um cachorro que preenche sua realidade. Uma ideia ligada a 
essa situação era valorizar a imaginação infantil, mas frisar que a realidade é muito importante, até porque é ela quem alimenta a imaginação. $E$ que nada substitui o afeto. Como me disse ontem uma crítica e blogueira, "é uma elegia à vida".

(CASARIN, 2018, s/p.)

Vale lembrar que o tema do amigo invisível, segundo especialistas da área, é um fenômeno ainda pouco explorado na literatura internacional em Psicologia e Psiquiatria. Existem ainda questões importantes "sobre quem são as crianças que criam companheiros imaginários e o papel que a fantasia desempenha no desenvolvimento emocional e cognitivo" (VELLUDO, 2019, p.i). Nesse sentido, foi realizada uma pesquisa com quarenta crianças entre 6 e 7 anos, 21 meninas e 19 meninos, recrutadas em uma escola pública primária de uma cidade localizada no estado de São Paulo . Constatou-se que, dos quarenta,

[d]ezoito participantes foram incluídos no grupo de crianças que relataram um companheiro imaginário e 22 no grupo de crianças que não o fizeram. [...] Crianças com acompanhantes imaginários apresentaram escores de vocabulário mais elevados do que crianças que não os relataram, mas não foram encontradas diferenças significativas entre os dois grupos em relação à teoria da mente e à compreensão emocional. (VELLUDO, 2014, p.42) 
O que se depreende da pesquisa é que o companheiro imaginário está presente no cotidiano de $45 \%$ das crianças participantes da amostra pesquisada. Dentre outras evidências, observou-se que "a criação de companheiros imaginários não está associada a nenhum déficit de desenvolvimento; pelo contrário, pode ser um preditor de habilidades mais sofisticadas, como vocabulário mais alto" (VELLUDO, 2014, p.55).

Como a arte reflete esteticamente a realidade, temas e problemas do cotidiano e a presença do amigo imaginário ganham também as páginas das obras da literatura infantil, recriados pela imaginação do autor. As reações do público diante de uma obra de arte variam de acordo com a maturidade e as histórias de vida e de leituras de cada um. Por isso, para o artista, as reações em relação a sua obra podem surpreendê-lo, como ocorreu com os escritores da literatura infantil e juvenil nos últimos anos. As mídias sociais exacerbaram as reações que alcançaram patamares não imaginados, como ocorreu com essa obra de Ana Maria Machado. Surpresa com a repercussão da leitura do livro publicado na década de 1980, quando perguntada o que teria a dizer aos pais que a acusam, respondeu:

Não sei muito o que dizer, a não ser que há um ponto de partida positivo: os pais fazem 
bem em se preocupar com o que os filhos leem e devem mesmo ler junto com eles. $E$ também, ler sozinhos, ler mais, se acostumar muito com a leitura de literatura - para perder o medo da linguagem simbólica e entender como funciona a linguagem nessa função de contar histórias e fazer ficção (ou seja, inventar enredos e personagens que não são reais). Se uma criança gosta de livros de sereias, não quer dizer que deseje se afogar para viver no fundo do mar. Se outra ama histórias de anjinhos, não significa que quer se jogar de uma montanha sobre uma nuvem para viver com eles. Mas, por outro lado, qualquer pessoa de bem deve saber do que fala antes de espalhar acusações graves e levianas desse tipo. Até mesmo porque é crime acusar alguém de um crime grave como esse (como indução a suicídio de menor). (CASARIN, 2018, s/p.)

Um outro livro incluído no rol dos "proibidos" é Peppa, de Silvana Rando que, depois de muito tempo no mercado, foi alvo de críticas nas mídias sociais e acabou sendo tirado de circulação pela autora, graças a uma polêmica gerada pelos vídeos postados por uma youtuber em seu canal da Internet.

Publicada em 2009, o enredo tem como protagonista Peppa, uma menina que tem o cabelo mais forte do universo! Com eles, podia fazer coisas incríveis como brincar de cabo de guerra, carregar carrinho de feira e ajudar na mudança da família. A vida da menina segue como a de qualquer criança 
de sua idade até que um dia, andando pela rua, um cartaz que promete tratar qualquer tipo de cabelo desperta sua atenção, e ela decide alisar suas madeixas encaracoladas. Para isso junta as economias do cofrinho e, depois de "dezesseis horas e quarenta minutos" de tratamento no cabeleireiro, descobre que, para manter o cabelo liso, teria de seguir uma longa lista de proibições: não podia entrar no mar, nadar, tomar chuva, rolar na grama, correr e nem rir demais. Triste por não poder brincar como as outras crianças, só lhe restava se sentar no banco da pracinha e observar o movimento. Num dia de calor intenso, Peppa, muito irritada com aquela situação, sai correndo, pulando, gritando e mergulha na piscina. Seus cabelos voltam a ser como antes, e ela recupera a alegria de viver.

A narrativa verbal é linear, uma sequência de fatos sem saltos temáticos ou idas e vindas no tempo que possam dificultar a compreensão do leitor iniciante. Tudo é muito bem "costurado" para alcançar o clímax final em que a protagonista faz as pazes com seu cabelo encaracolado que a diferencia dos amigos, mas marca a sua identidade e, que ao ser recuperado, devolve-lhe o convívio com os amigos e a alegria de ser criança.

O texto verbal e as ilustrações trazem o traço característico do humor que a autora imprime em sua obra. Esse recurso 
aparentemente ingênuo da estrutura comunicativa da obra literária reflete-se como campo propício para a crítica e o questionamento. São artimanhas da construção textual em que, através do jogo da linguagem, se revela a arte literária. É o que se observa no trecho a seguir, quando a menina decide alisar os cabelos:

A cabeleireira, um pouco espantada, avisou que daria muito trabalho, mas era possível sim, obter um ótimo resultado.

E que trabalho! Foram dezesseis horas e quarenta e oito minutos.

Ufa! Agora sim, seu cabelo estava incrível! (RANDO, 2009, p.14-15)

O exagero típico dos desenhos de humor está presente aqui não só nas ilustrações, mas também na linguagem verbal, marcada especialmente pela frase "foram dezesseis horas e quarenta minutos", tempo gasto pela cabeleireira para conseguir mudar a aparência do cabelo de Peppa (RANDO, 2009, p.15). A presença da interjeição “Ufa!", aliada ao uso da pontuação, intensifica o viés humorístico da cena narrada.

As ilustrações também exacerbam as características do cabelo, que é proporcionalmente muito maior do que o corpo da menina, e reduplicam o jogo literário do texto. O caráter libertário da arte, que ludicamente liberta o homem da sua 
condição humana, está presente na economia de traços fisionômicos das personagens que se aproximam do traço infantil. O humor tem esse potencial, através do exagero, da mentira implícita nas linguagens verbal e visual, permite ao leitor fazer um balanço entre a verdade e a falsidade, entre o igual e o diferente; ele expressa mais do que diz. E é esse não dito que abre múltiplas possibilidades de sentido e de interpretação.

Entretanto, o humor que a linguagem verbal ou visual expressa só se realiza completamente na recepção, ou seja, não basta a intenção daquele que produz é preciso que o receptor perceba a intenção e reaja. É no efeito correspondente que ele se realiza. Por isso é variável, permite muitas interpretações e provoca reações, muitas vezes diversas das pretendidas pelo produtor. Vale ressaltar também que, quando um autor coloca o ponto final em uma obra, ele não tem controle sobre a sua recepção. É na interação com o leitor, que a obra se realiza plenamente. É preciso correr riscos, escrever sem receitas ou demandas do mercado e se aventurar sem medo, como fizeram os autores dessas obras. Ao leitor, cabe-lhe caminhar pelas veredas do texto, complementar os espaços vazios entre palavras com suas experiências de vida e de leituras, se identificar ou 
não com a trajetória dos personagens e se emocionar com a história narrada. A obra de qualidade literária provoca reações através do texto e, a voltada para esse público específico, através também da ilustração.

Peppa, assim como Meninos sem pátria e $O$ menino que espiava pra dentro também sofreu o poder das mídias sociais. Das três obras, foi a que acabou por ser retirada do mercado por decisão da autora, por conta das polêmicas geradas a partir da veiculação de um vídeo com a análise da obra feita pela youtuber Ana Paula Xongani. A leitura do livro, segundo Xongani, seria inadequada para as crianças, identificando na narrativa pontos de cunho racista. Em matéria publicada no jornal O Tempo naquela época, afirmou: "Vi que crianças negras poderiam se sentir incomodadas com a questão de como o cabelo crespo é tratado ali. O que é tratado de forma lúdica pela autora pode ser visto de forma dura por meio da vivência de uma criança negra" (O TEMPO, 2017, s/p.).

A polêmica cresceu, ganhou as páginas dos meios de comunicação, de revistas como Carta Educação ${ }^{1}$, Nova Escola, Superinteressante, do jornal O tempo, de portais de notícias como G1, Folha de São Paulo, Folha MT, UOL Entretenimento, além de inúmeros blogs que replicaram

1 SCORCE, Carol (2017). "Peppa será retirado do mercado após acusação de racismo". Carta Educação. In http://www.cartaeducacao.com.br/reportagens/peppa-sera-retirado-domercado-apos-acusacao-de-racismos/ Acesso em 21.Out.2018. 
entrevistas de jornais; sem contar com as manifestações do público pelo Facebook da youtuber e da autora.

Em novembro de 2017, Pâmela Carbonari, da revista Superinteressante, entrevistou a autora e informou:

O vídeo tem mais de 300 comentários, a favor e contra as afirmações. Depois dele, o livro recebeu avaliações negativas nos sites das principais livrarias do país. Por outro lado, escritores, pais e professores que trabalhavam Peppa em sala de aula se manifestaram em apoio à obra. A autora conta que o livro estava entre os mais lidos no Hospital de Câncer de Sorocaba, porque ajudava as crianças que estavam perdendo o cabelo a aceitarem que elas não precisavam ser iguais às outras crianças. (2017, s/p.)

Para uns, o livro aborda o empoderamento feminino, o amor próprio, o respeito e a aceitação de padrões, e a leitura veiculada no vídeo é equivocada e unilateral. Para as professoras que utilizavam o livro, as alunas negras que alisavam os cabelos deixaram de fazê-lo, após a leitura do livro, justamente por perceberem que é muito melhor aceitar as suas próprias características. Para muitos, a leitura do livro feita pela youtuber não demonstra o conteúdo real da obra e lamentaram o fato de a autora ter retirado o livro de circulação, depois de várias tentativas de conversar sobre o livro com a youtuber. 
Silvana, por sua vez, nos depoimentos a seguir, conta como viu a polêmica: "As críticas acabaram muito focadas na questão do cabelo, sem se aprofundarem na história, que trata justamente das questões estéticas que são impostas desde cedo às meninas" (CARBONARI, 2017, s/p.). E prossegue esclarecendo:

Nunca havia recebido este tipo de crítica. Ao contrário, fui convidada a ir a escolas justamente para falar de autoestima com as crianças. Mas sei que o cabelo tem uma simbologia forte para o movimento negro, e jamais quis que meu livro transmitisse qualquer coisa que fosse ofensiva nesse sentido.

$[\ldots]$

O livro em questão fala da vaidade exagerada na infância, de trocar a liberdade de ser criança pelos padrões de beleza [...] O preço que pagamos por tentarmos entrar num molde que não nos pertence. Gostar de como somos é tão maravilhoso que quis deixar isso num livro para as crianças. (2017, s/p.)

Muitas vozes se levantaram em defesa da autora e contra a censura no meio literário. Entre elas está o autor Ilan Brenman que, em entrevista ao jornal $O$ tempo, replicada no site de notícias G1, declarou: "Minha filha pequena que tem cabelo crespo amava esse livro, é um livro que fortalece as crianças e não as rebaixam" (2017, s/p.). E prossegue dizendo:

Peppa é um livro que exalta a identidade infantil, fala de uma jornada de busca por 
identidade e com muito humor (pecado mortal hoje ter humor). A blogueira fez uma leitura rasa e enviesada da obra da Silvana. [...] Se não pararmos com isso agora será um pandemônio literário. Os livros produzem ruídos, incômodos, sensações e pensamentos. Precisamos fortalecer as crianças com livros que criem imunidade simbólica. O que estamos fazendo é uma eugenia literária. (2017, s/p.)

O clima de polarização tomou conta das redes sociais, e Peppa, como as outras obras analisadas, não é o único caso. A literatura, ao refletir esteticamente as contradições, as misérias e as grandezas acerca do mais profundamente humano, emociona e provoca reações diversas nos leitores. Mas esse não é o papel da ficção? Qual seria, então, o sentido de rotular Meninos sem pátria, $O$ menino que espiava pra dentro e Peppa como obras não recomendáveis para crianças?

A tendência de rotular obras literárias com adjetivos cresce a cada dia. A literatura sem rótulos é um direito que não deve ser negado ao leitor, pois cabe a ele fazer suas escolhas A ficção ajuda a compreender a grandeza e os fracassos humanos, a expandir os limites da experiência do leitor na medida em que ele pode viver novas experiências que não são as suas, num tempo e num espaço que não é o seu. 


\section{REFERÊNCIAS}

BOLAÑO, César (Org.) (1999). Globalização e regionalização das comunicações. São Paulo: EDUC/UFS.

CANDIDO, Antonio et al. (1968). A personagem de fiç̧ão. São Paulo: Perspectiva.

CARBONARI, Pâmela (2017). "Autora tira livro de circulação após polêmica sobre racismo". Super Interessante. In https://super.abril.com. br/sociedade/autora-tira-livro-de-circulacao-apos-polemica-sobreracismo/ Acesso em 21.Out.2018.

CASARIN, Rodrigo (2018). "Ana Maria Machado sobre acusações: tão absurdo que não sei como reagir". Página Cinco. In https:// paginacinco.blogosfera.uol.com.br/2018/09/07/ana-maria-machadosobre-acusacoes-tao-absurdo-que-nao-sei-como-reagir/ Acesso em 16.Dez.2019.

FUSER, Bruno (2005). "Sociedade em rede: perspectivas de poder no espaço virtual". In: FILDALGO, António; SERRA, Paulo (Orgs.). Ciências da Comunicação em Congresso na Covilhã Actas do III Sopcom, VI Lusocom e II Ibérico: Volume III - Visões Disciplinares. p.39-49. In https://www. researchgate.net/profile/Xose_Perez2/publication/242757820_A_ representacion_da_realidade_galega_na_Television_de_Galicia/ links/55eec60508ae199d47bf28cd/A-representacion-da-realidadegalega-na-Television-de-Galicia.pdf\#page=39 Acesso em 12.Dez.2019.

G1 (2017). "Acusação de racismo faz autora tirar livro 'Peppa' de circulação". In https://g1.globo.com/educacao/noticia/acusacao-deracismo-faz-autora-tirar-livro-peppa-de-circulacao.ghtml Acesso em 22.Jan.2020.

ISER, Wolfgan (1979). A literatura e o leitor: textos da Estética da Recepção. Costa Lima (Trad.). Paz e Terra.

LUNETAS (2018). "Caso Luiz Pimentel: de onde vem a ofensiva contra os livros infantis?". In https://lunetas.com.br/livro-meninos-sem-patria/ Acesso em 12.Dez.2019. 
MACHADO, Ana Maria (2008). O menino que espiava pra dentro. São Paulo: Global.

MOLICA, Fernando (2018). "Escola católica do Rio censura livro acusado de ser de esquerda: direção do Colégio Santo Agostinho acatou queixas de pais de alunos que protestaram contra a adoção de obra de ficção que trata da ditadura". Veja. In https://veja.abril.com.br/brasil/escolacatolica-do-rio-censura-livro-acusado-de-ser-de-esquerda/ Acesso em 12.Dez.2019.

O TEMPO (2017). "Silvana Rando retira livro 'Peppa' de circulação: autora e editora tiraram a obra do mercado após polêmica por questões raciais". In https://www.otempo.com.br/divers\%C3\%A3o/magazine/silvanarando-retira-livro-peppa-de-circula\%C3\%A7\%C3\%A3o-1.1546128/ Acesso em 21.Out.2018.

PUNTEL, Luiz (1988). Meninos sem pátria. 9.ed. São Paulo: Ática. RANDO, Silvana (2009). Peppa. São Paulo: Brinque-Book.

VELLUDO, Natália Benincasa (2014). "A criação de amigos imaginários: um estudo com crianças brasileiras". Repositório Institucional UFSCar. Dissertação (Mestrado em Psicologia). Centro de Educação e Ciências Humanas, Programa de Pós-Gradução em Psicologia. São Carlos, SP. In https://repositorio.ufscar.br/handle/ufscar/6052 Acesso em 16.Nov.2019.

Rosa Maria Cuba Riche é Doutora em Letras Vernáculas (Ciência da Literatura - UFRJ, mestre em Letras Vernáculas (Literatura Brasileira UFRJ. Professora Assistente de Língua Portuguesa e Literatura Brasileira do CAp-UERJ, atuando no Programa de Pós-Graduação de Ensino em Educação Básica (PPGEB). Dos livros publicados, destacam-se: Oficina da Palavra: ler e escrever bem para viver melhor, Editora FTD; Brasil em cantos e versos: natureza, Editora Melhoramentos; Oficina de textos: leitura e redação, (4 volumes) Ed. Saraiva; Análise e produção de textos, Ed. Contexto, além de capítulos de livros, artigos publicados em revistas acadêmicas e periódicos. Membro do GT de Leitura e literatura infantil e juvenil da ANPOLL. Membro integrante do Grupo de Pesquisa "A narrativa ficcional para crianças e jovens: teorias e práticas Culturais para crianças", coordenado pela Professora Doutora Regina Michelli (UERJ) e do Grupo de Pesquisa LEDEN - Linguagem e Educação: Ensino 
e Ciência, coordenado pelos Professores Doutores Esequiel Rodrigues Oliveira e Andrea da Silva Marques Ribeiro (CAp-UERJ). Tem experiência na área de Letras, com ênfase em Língua Portuguesa, Prática de Ensino em Língua Portuguesa e Literatura Brasileira, Literatura infantojuvenil. Lattes: http://lattes.cnpq.br/7849433194138639.

E-mail: rosacubariche@gmail.com

ORCID iD: https://orcid.org/0000-0002-4919-4243

Recebido em 27 de janeiro de 2020. Aprovado em 11 de julho de 2020. 